\title{
A comparison of hemispatial neglect from posterior parietal and periarcuate lesions in the monkey
}

\author{
DOUGLAS P. CROWNE and LINDA W. MAH \\ University of Waterloo, Waterloo, Ontario, Canada
}

\begin{abstract}
In this experiment, we examined hemispatial neglect in the monkey, comparing unilateral parietal lesions with lesions of frontal cortex. Our purpose was to resolve the apparent puzzle of grave parietal symptoms in humans shown only inconsistently in monkeys. We quantitatively compared visual neglect and recovery in monkeys with unilateral posterior parietal, periarcuate, and principal sulcus (control) lesions. Neocortical lesions of these three regions were produced in 9 macaque monkeys, and they were tested for their ability to detect and respond to brief visual stimuli in varying field eccentricities. Both parietal and arcuate lesions resulted in neglect. Recovery from the arcuate lesion occurred by the 3rd postoperative week, but neglect was strongly evident in the parietal animals in the 8th week. A second homologous lesion produced a more severe and enduring neglect of contralateral stimuli and also reinstated neglect in the hemifield affected by the first lesion. These data confirm symptoms of visual neglect from parietal lesions and are consistent with differentiated functions of posterior parietal and arcuate cortex in spatial attention.
\end{abstract}

The symptoms of neglect from right parietal lesions so impressed Critchley (1953) in their severity and bizarreness that he likened them to a psychosis. Visual and auditory neglect of space on the left side, failure to recognize or dress the left side of the body (a gross distortion of the body image), and denial of illness seemed more like a grave psychotic disorder than a neurological perceptual one. Critchley's analogy was well taken, summoning us as it did to appreciate the consequences of damage to perceptual and somatosensory regions of the brain.

Other areas remote from the parietal lobe are also involved in responsiveness to events in one half of space and to one side of the body. The most notable of them is a small region of dorsolateral frontal cortex, area 8. Damage here also produces contralateral neglect, described by Silberpfennig (1941) in 2 patients but reported far earlier in the monkey by Bianchi (1895). This is a rarer form of neglect in humans and differs from the symptoms of parietal lesions (Heilman, Watson, \& Valenstein, 1993). Deviation of the head and eyes toward the damaged side occurs with frontal but not parietal lesions; denial of illness and of limbs on the affected side of the body are parietal and not frontal symptoms (Heilman et al., 1993).

It was surprising to discover, then, that while frontal lesions in the monkey reliably produce neglect (Crowne, 1983; Heilman et al., 1993), the evidence on neglect from parietal lesions was equivocal. Although several experiments showed neglect in the contralateral half-field from parietal lesions (Denny-Brown \& Chambers, 1958; Deuel,

This research was supported by Grant A 8262 from the Natural Sciences and Engineering Research Council of Canada. Correspondence should be addressed to D. P. Crowne, RR\#1, St. Agatha, ON NOB 2L0, Canada (e-mail: dcrowne@watarts.uwaterloo.ca).
1987; Deuel \& Regan, 1985; Valenstein, Heilman, Watson, \& Van den Abell, 1982), an even greater number did not (Drewe, Ettlinger, Milner, \& Passingham, 1970; Ettlinger \& Kalsbeck, 1962; Faugier-Grimaud, Frenois, \& Peronnet, 1985; Faugier-Grimaud, Frenois, \& Stein, 1978; Heilman, Pandya, Karol, \& Geschwind, 1971; Lamotte \& Acuña, 1978; Lynch, 1980; Lynch \& McLaren, 1989; Stein, 1978). However, the attenuated form of neglect, extinction, in which bilateral simultaneous stimulation evokes only responses to the side ipsilateral to the lesion, has been consistently observed (Denny-Brown \& Chambers, 1958; Deuel, 1987; Deuel \& Regan, 1985; Eidelberg \& Schwartz, 1971; Heilman et al., 1971; Lynch, 1980; Lynch \& McLaren, 1989; Schwartz \& Eidelberg, 1968).

In this experiment, we examined hemispatial neglect in the monkey, comparing unilateral parietal lesions to lesions of frontal cortex. Our purpose was to resolve the apparent puzzle of grave parietal symptoms in humans shown, perhaps less consistently, in monkeys.

\section{METHOD}

\section{Subjects \\ Nine macaque monkeys, 8 juvenile male Macaca fascicularis 2-2.5 years of age and 1 adult female Macaca assamensis age 6 years, were subjects in the experiment. Their weights ran from 2.5 to $6.4 \mathrm{~kg}$. They were housed in the University of Waterloo Depart- ment of Psychology primate colony in individual cages, maintained on a 12:12-h light:dark cycle, and fed a diet of commercial monkey chow routinely given immediately after daily testing in late morn- ing or early afternoon. They were taken to the testing apparatus in pri- mate transport cages and transferred without handling to the test cage.}

\section{Apparatus and Procedure}

Training and testing were conducted in a modified housing cage. On its far wall was a $90^{\circ}$ semicircular panel of 19 recessed and backilluminated buttons. Thirteen of the buttons - center and six on each 
side - were operative. In training, the monkeys were first required to press the illuminated center button for banana-pellet reward. Next, pressing the center button illuminated a second button, appearing in random positions in the array. Responding to the second button was rewarded. Training continued until the monkeys responded to the second button on every trial and at asymptotic latency. They were then switched to a second 19-button panel subtending $180^{\circ}$. Placed immediately in front of the button array was a flat panel of heavygauge aluminum with a slot $5 \mathrm{~cm}$ high extending $55 \mathrm{~cm}$ from one end of the button array to the other, through which the monkeys could reach to press the buttons. Placed just above the slot at the center was an oval cutout, $8 \times 7 \mathrm{~cm}$, giving a view of the array. Latency was reduced to asymptote (less than $300 \mathrm{msec}$ for the most proficient monkeys and nearly $500 \mathrm{msec}$ for the slowest) using a diminishing time limit, and training was begun on a concurrent conditional position discrimination (Crowne, Dawson, \& Richardson, 1989), the testing on which began at the conclusion of the first phase of this experiment. When the animals had mastered the discrimination, preoperative latencies were recorded for 10 successive days, following which unilateral lesions were undertaken. Testing began 4-10 days postoperatively and continued for 8 weeks at 49 trials per day, 5 days a week. Throughout postoperative testing, the second button remained lit for $5 \mathrm{sec}$, and an additional $.5 \mathrm{sec}$ was allowed for the monkey's response, giving a maximum latency of $5.5 \mathrm{sec}$ if the monkey failed to respond. Following criterion on the discrimination problem, the monkeys received a second, homologous, lesion, and a further 8 weeks of neglect testing ensued. Stimulus presentation, randomization, delivery of reward, and recording of the experimental measure, latency, were programmed by computer. Apparatus and training have been described in previous articles (Crowne et al., 1989; Crowne, Yeo, \& Russell, 1981).

\section{Surgery}

Serial lesions were carried out aseptically under metofane and nitrous oxide inhalation anesthesia. Three monkeys sustained lesions of posterior parietal cortex (area PG or 7a), 3 of periarcuate cortex (area 8), and 3 of the principal sulcus, the control lesion. The cortex was exposed by trephine and rongeurs, and after retraction
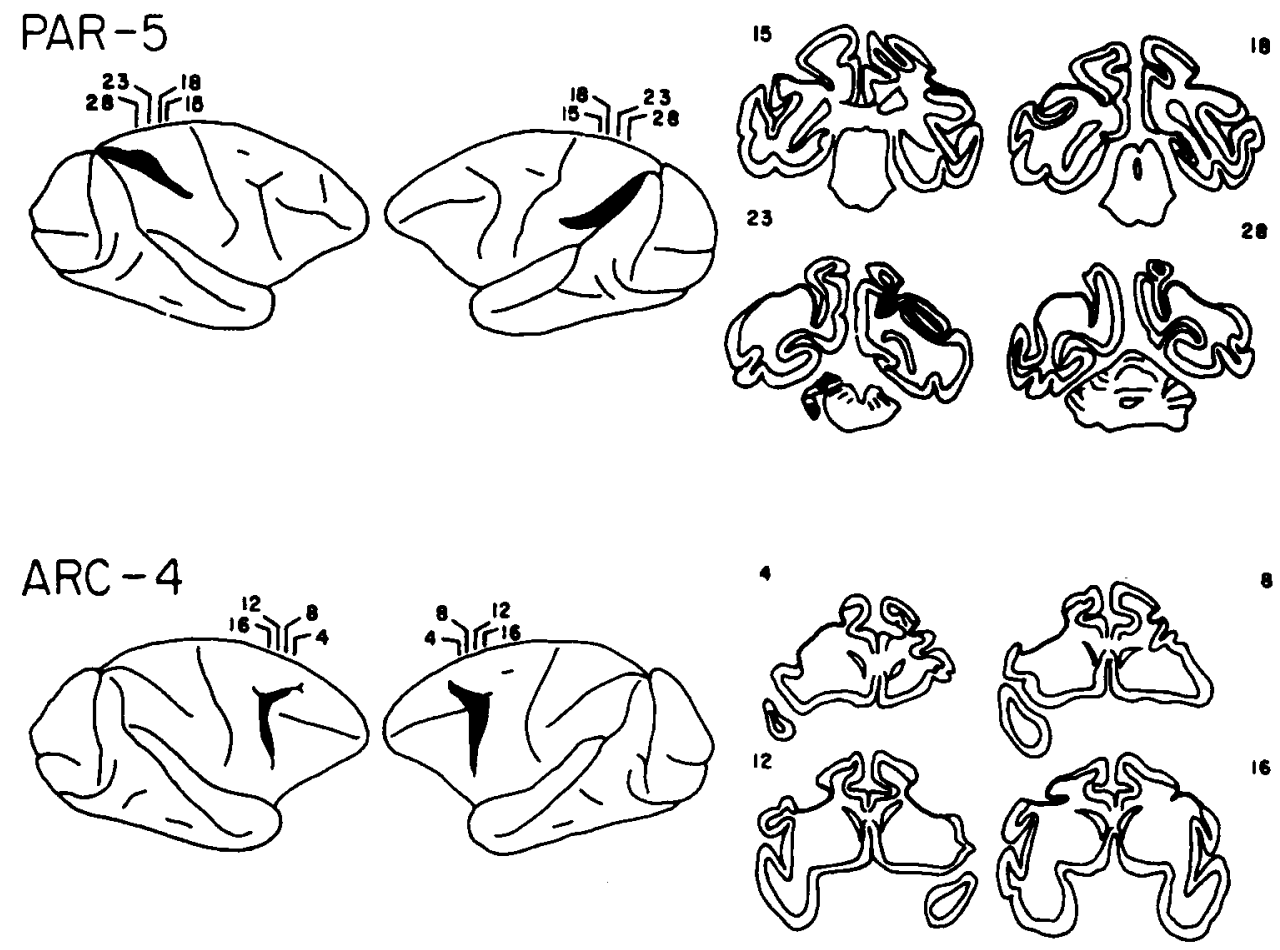

PRIN-3
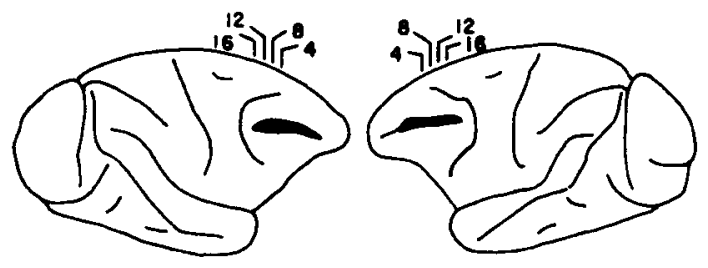

4
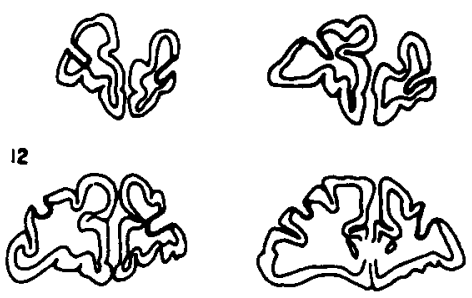

10

Figure 1. Lateral views and coronal sections of representative lesions in each group. Lateral views were reconstructed from photographs of the brains and from coronal sections. PAR, parietal; ARC, arcuate; PRIN, principal sulcus. 
of the dura, aspirated with a fine glass pipette. The incised dura was approximated with individual sutures, and muscle, subcutaneous tissues, and skin were closed in anatomical layers. Long-acting bicillin $(300,000 \mathrm{U}$, i.m. $)$ was then administered.

The intended area of the posterior parietal (PAR) lesions was somewhat more extended than PG, to include polysensory cortex immediately inferior to it, from the parieto-occipital notch ventrally along the anterior banks of the superior temporal sulcus and lateral sulcus to the level of the bottom of the intraparietal sulcus. The area of these lesions incorporated POa/LIP (Andersen, 1995; Pandya \& Yeterian, 1985) in the lateral intraparietal sulcus and VIP (Maunsell \& Van Essen, 1983) in its fundus. The periarcuate (ARC) lesions were aimed at the anterior bank and depth of the arcuate sulcus from the tip of the superior ramus to the tip of the inferior branch, removing approximately $3 \mathrm{~mm}$ of cortex rostral to the sulcus. Principal sulcus (PRIN) lesions were to extend its full length, including both banks and penetrating to its depth. In summary, the animals in the three groups each received two lesions, the second homologous to the first and carried out not less than 8 weeks after the first.

\section{Histology}

At the conclusion of this and the companion experiment, the monkeys were sacrificed by lethal barbiturate dose and perfused through the heart with saline and $10 \%$ formalin. The removed brains were immediately photographed on each side before hardening in formalin. Coronal sections of $40 \mu \mathrm{m}$ were taken through the lesions, saving every 10 th for staining by metachromatic thionin. Lateral views of the lesions were reconstructed from the photographs and from the sections; coronal views were traced from sections $1.6 \mathrm{~mm}$ (arcuate and principal sulcus) or $2.0 \mathrm{~mm}$ (parietal) apart. Figure 1 shows representative reconstructions of the three lesions.

The PAR lesions of Monkey 71 destroyed the intended areas, as did the first lesion (right) in Monkey 5; the second lesion in this animal was somewhat smaller. In Monkey 6, the lesions were considerably larger on each side, extending caudally through middle superior temporal cortex to the lunate sulcus on the right and into somatosensory cortex anterior and inferior to the intraparietal sulcus on the left. On both sides, the lesions were deep, impinging on white matter. Monkey 6 was more impaired after each lesion than the other 2 animals, its greater deficit continuing in each case for the full 8 weeks. In all 3 animals, cortex of the lateral bank and the fundus of the intraparietal sulcus, including POa/LIP and VIP, was destroyed. The ARC lesions were as intended in Monkeys 4 and 41 ; in Monkey 2, they extended further rostrally and into white matter in both hemispheres and invaded area 6 on the right. The behavioral effect of ARC-2's larger lesions, however, was minimal, showing only in a greater deficit during the 1st week after the initial lesion. The PRIN lesions were as intended.

\section{RESULTS}

The data of the experiment are the latencies of the 3 monkeys in each lesion group representing the preoperative baseline succeeded by 8 weeks of observations following both the first and second lesions. There was a complete set of latencies for every animal. To simplify the analyses and presentation of the data, the 12 button stimuli were combined in four groups: the three outermost buttons on the same side as the lesion, wide ipsilateral (WI); the three ipsilateral buttons adjacent to the center button (CI); the outermost three contralateral to the lesion (WC); and the near-center buttons on the contralateral side (CC). "Contralateral" and "ipsilateral" refer to the lesion immediately under consideration (e.g., contralateral to the first lesion). The distribution of response latencies was positively skewed, necessitating a logarithmic transformation. The data entered for analysis were mean log-transformed latencies for the four stimulus groups averaged for the 10 preoperative days and for each postoperative week. The stimulus position means of the first and second lesions for each group are presented in Figures 2-4.

The first-lesion panels of Figures 2 and 3 show marked latency increases contralateral to the lesions in both the PAR and ARC groups and a modest ipsilateral increase in the PAR group for the 1 st week. Recovery largely appears to occur in the ARC group but not in the PAR. It is evident that lesion effects in the PRIN group, seen in Figure 4, were minimal. The second lesions in the PAR and

\section{FIRST LESION}

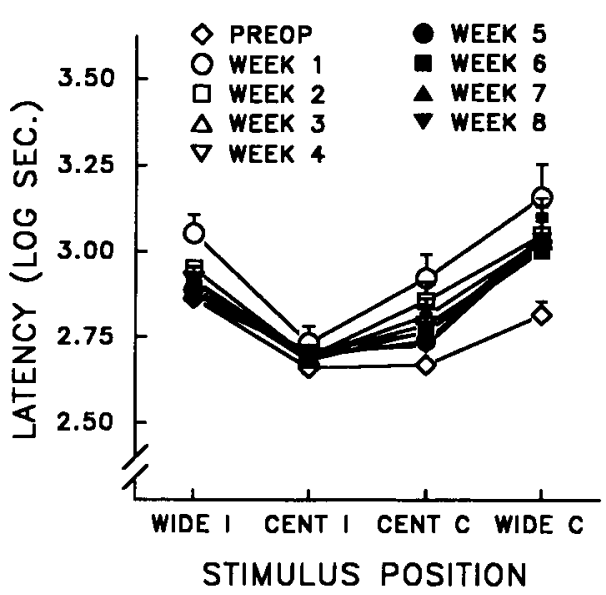

\section{SECOND LESION}

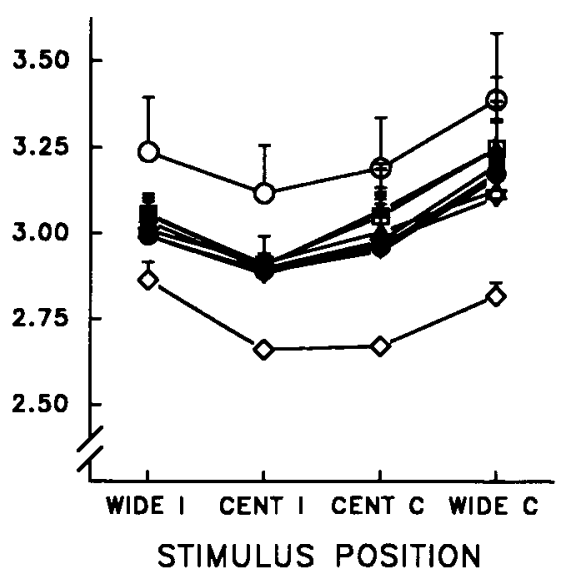

Figure 2. Mean latencies at each stimulus position preoperatively and for 8 postoperative weeks for the first and second lesions in the parietal group. I, ipsilateral; $\mathrm{C}$, contralateral; Cent, central. 

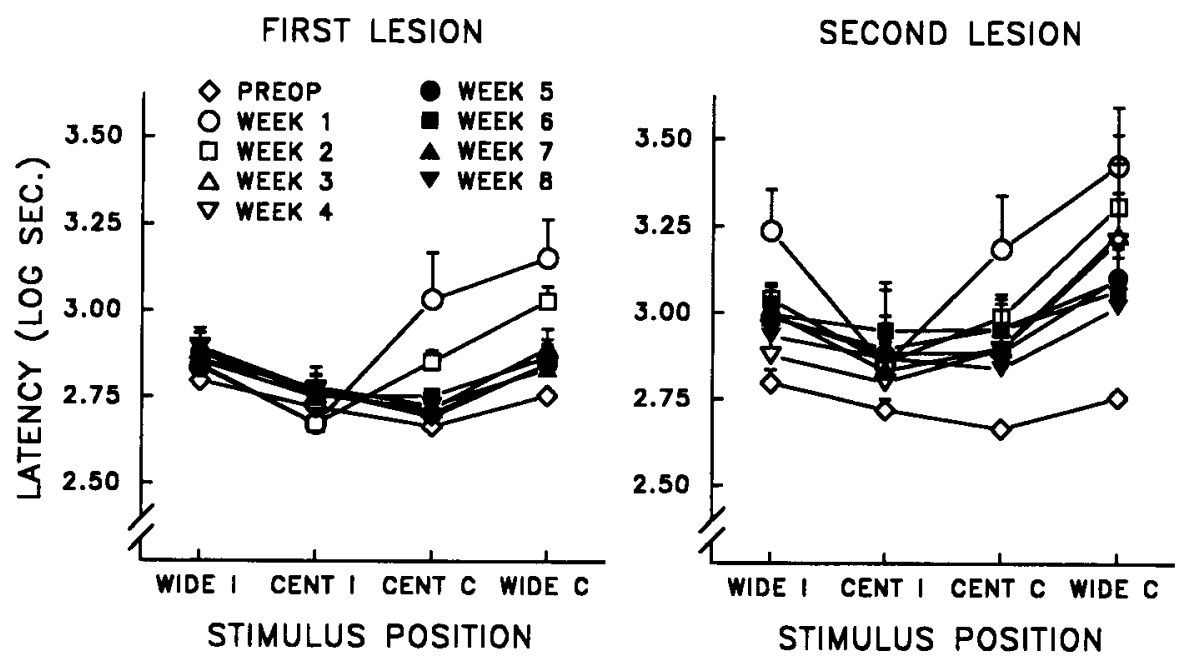

Figure 3. Mean latencies at each stimulus position preoperatively and for 8 postoperative weeks for the first and second lesions in the arcuate group. I, ipsilateral; C, contralateral; CENT, central.

ARC groups (Figures 2 and 3) produced very large increases in contralateral latencies throughout the 8 weeks, accompanied by increased ipsilateral latencies. Even responses to more central stimuli were affected. The second PRIN lesion resulted in slightly increased latencies to the central and wide contralateral buttons, decreasing weekly.

The first analysis compared the lesion groups on preoperative latencies; no difference was found $[F(2,66)=$ $.56, p=.60]$. A lesion groups $\times$ weeks $\times$ stimulus position $X$ operation analysis of variance (ANOVA) yielded a significant group $\times$ week $\times$ position interaction $[F(42,126)=2.46, p=.0001]$; there was also a significant operation main effect $[F(1,6)=6.97, p=.04]$. Within-group differences between pre- and postopera- tive latencies for each week were analyzed by Dunnet's test. Significant postoperative differences from preoperative (control) latencies are shown in Table 1 and summarized below.

\section{PAR}

First lesion. Response latencies to wide and central contralateral buttons increased substantially, with recovery shown only to the $\mathrm{CC}$ group of buttons in the 4 th week. Latencies to WI buttons were elevated for the 1 st week.

Second lesion. A far greater deficit was observed, with significantly increased latencies to both contralateral and ipsilateral stimuli. All latencies over the entire 8 weeks were longer than those in the preoperative period except to WI buttons in Weeks 4, 5, and 8 .
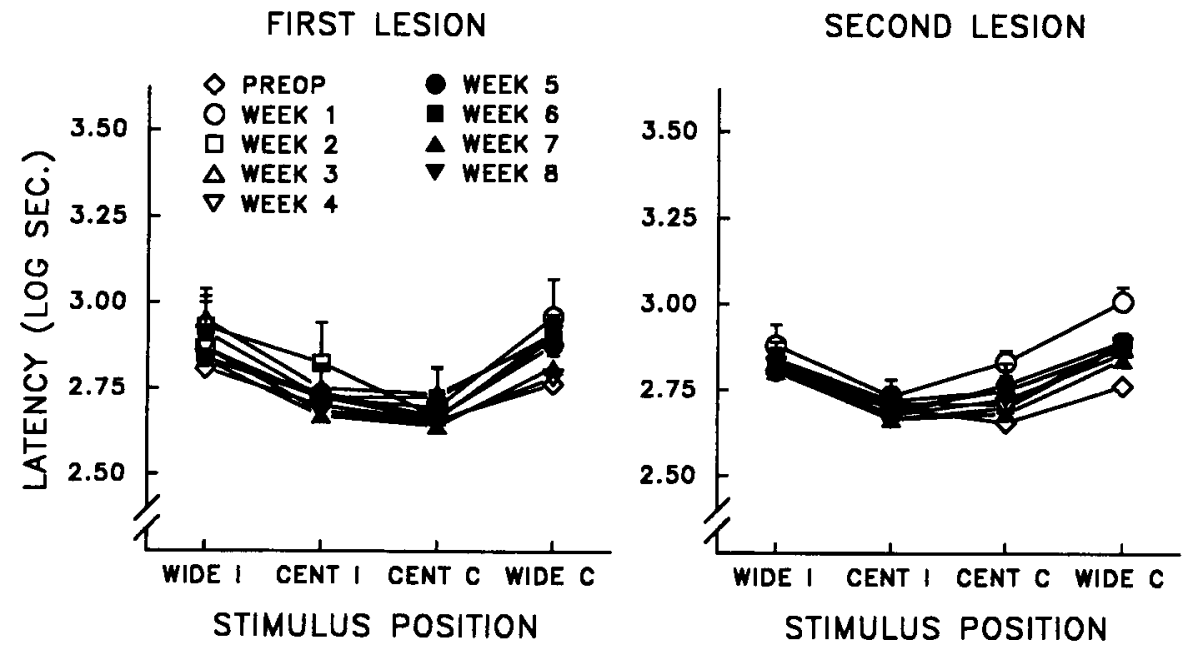

Figure 4. Mean latencies at each stimulus position preoperatively and for 8 postoperative weeks for the first and second lesions in the principal sulcus group. I, ipsilateral; C, contralateral; CENT, central. 
Table 1

Preoperative Log Response Latencies and Postoperative Latencies Significantly Different From the Preoperative

\begin{tabular}{|c|c|c|c|c|c|c|}
\hline \multirow[b]{2}{*}{ Lesion } & \multirow[b]{2}{*}{ Operation } & \multirow[b]{2}{*}{ Week } & \multicolumn{4}{|c|}{ Stimulus Position } \\
\hline & & & WI & CI & $\mathrm{CC}$ & WC \\
\hline \multirow[t]{3}{*}{ PAR } & Preop & 0 & 2.863 & 2.660 & 2.670 & 2.817 \\
\hline & 1 & $\begin{array}{l}1 \\
2 \\
3 \\
4 \\
5 \\
6 \\
7 \\
8\end{array}$ & 3.053 & & $\begin{array}{l}2.923 \\
2.857 \\
2.813\end{array}$ & $\begin{array}{l}3.160 \\
3.050 \\
3.033 \\
3.010 \\
3.030 \\
3.003 \\
3.043 \\
3.033\end{array}$ \\
\hline & 2 & $\begin{array}{l}1 \\
2 \\
3 \\
4 \\
5 \\
6 \\
7 \\
8\end{array}$ & $\begin{array}{l}3.237 \\
3.057 \\
3.010\end{array}$ & $\begin{array}{l}3.117 \\
2.910 \\
2.913 \\
2.880 \\
2.890 \\
2.897 \\
2.907 \\
2.887\end{array}$ & $\begin{array}{l}3.190 \\
3.050 \\
3.003 \\
2.973 \\
2.960 \\
2.977 \\
3.007 \\
2.947\end{array}$ & $\begin{array}{l}3.387 \\
3.247 \\
3.123 \\
3.103 \\
3.173 \\
3.197 \\
3.247 \\
3.160\end{array}$ \\
\hline \multirow[t]{2}{*}{$\mathrm{ARC}$} & $\begin{array}{l}\text { Preop } \\
1\end{array}$ & $\begin{array}{l}0 \\
1 \\
2\end{array}$ & 2.797 & 2.720 & $\begin{array}{l}2.667 \\
3.033 \\
2.853\end{array}$ & $\begin{array}{l}2.757 \\
3.153 \\
3.030\end{array}$ \\
\hline & 2 & $\begin{array}{l}1 \\
2 \\
3 \\
4 \\
5 \\
6 \\
7 \\
8\end{array}$ & $\begin{array}{l}3.237 \\
3.040 \\
3.000 \\
\\
2.990 \\
2.997 \\
2.987 \\
2.993\end{array}$ & $\begin{array}{l}2.950 \\
2.897 \\
2.870\end{array}$ & $\begin{array}{l}3.187 \\
2.990 \\
2.900 \\
2.897 \\
2.883 \\
2.953 \\
2.957 \\
2.840\end{array}$ & $\begin{array}{l}3.427 \\
3.310 \\
3.227 \\
3.210 \\
2.887 \\
3.067 \\
3.097 \\
3.020\end{array}$ \\
\hline \multirow[t]{2}{*}{ PRIN } & $\begin{array}{l}\text { Preop } \\
1\end{array}$ & $\begin{array}{l}0 \\
1 \\
3 \\
6 \\
8\end{array}$ & $\begin{array}{l}2.807 \\
2.950\end{array}$ & 2.700 & 2.657 & $\begin{array}{l}2.763 \\
2.960 \\
2.910 \\
2.913\end{array}$ \\
\hline & 2 & 1 & & & 2.833 & 3.010 \\
\hline
\end{tabular}

Note-WI, wide ipsilateral; CI, central ipsilateral; CC, central contralateral; WC, wide contralateral; PAR, parietal; ARC, arcuate; PRIN, principal sulcus. All differences significant at $p<.05$.

\section{ARC}

First lesion. Latencies to contralateral buttons (WC and CC) significantly exceeded the preoperative period during Weeks 1 and 2 ; recovery occurred by the 3rd week. Responses to ipsilateral buttons remained at the preoperative level.

Second lesion. The second lesion produced more severe and enduring effects. Responses to WC and CC stimuli were greatly slowed during the entire 8-week testing period, with no evidence of recovery. Latencies to ipsilateral buttons were also greater than those in the preoperative baseline with the exception of Week 4 for WI and Weeks 1-4 for CI stimuli.

\section{PRIN}

First lesion. Only scattered increases in latency appeared, three for WC stimuli (Weeks 1, 6, and 8), and one for the WI buttons (Week 3), and these, although significant, were not appreciable.

Second lesion. Increases to only two groups of buttons (WC and CC) in the 1st week appeared; thereafter, the performance of the PRIN monkeys was not different from that of the preoperative baseline.

\section{DISCUSSION}

Our objective was a quantitative comparison of contralateral neglect from parietal and frontal lesions, essentially replicating in the monkey an earlier experiment in the rat (Crowne, Richardson, \& Dawson, 1986). In sharp contrast to a sizable majority of studies failing to show symptoms of neglect from parietal lesions, the present results agree with the far smaller minority in finding parietal neglect. The neglect from parietal lesions, either first or second, was in fact profound, with no recovery in the entire 8 weeks following the initial lesion and greater residual symptoms than those of animals with ARC lesions after the second lesion.

Visual neglect from ARC lesions is firmly established, with a history of qualitative observations and controlled quantitative experiments in the monkey going back more than 100 years (Crosby, 1953; Crowne, 1983; Latto \& Cowey, 1971; Smith, 1949). Why should parietal neglect, so striking and so much better known in humans, have resisted discovery in the monkey? The likely explanation is one offered by Rizzolatti and Gallese (1987). Cortex of the lateral bank of the intraparietal sulcus (area POa/ LIP) may be crucial for the appearance of neglect and has escaped damage in the negative studies. Remove it, as in this and the four earlier experiments with positive findings, and neglect appears; spare it and extinction to bilateral simultaneous stimulation will be the principal symptom. The use of sensitive measures like response latency will also contribute. It is particularly attractive to suppose that LIP, with its role in the planning of eye movements and in the representation of space in the coordinates of head and body (Andersen, 1995), is a critical region in parietal hemineglect, and perhaps the critical region. There are data, however, on which to argue that while both posterior parietal and frontal eye field lesions produce eye movement defects, these may simply parallel and not represent the prime cause of neglect (parietal, Deuel \& Regan, 1985; Weintraub \& Mesulam, 1989; frontal eye field, Latto \& Cowey, 1971). A deficit in spatial recognition and reaching, such as destruction of the ventral intraparietal area, VIP, might produce, could also result in neglect, although the animals were free to use the unaffected (or less affected, following the second lesion) hand. What seems probable is that areas within the intraparietal sulcus are implicated, and the definitive experiment will need to remove them selectively.

The topography of neglect from PAR and ARC lesions is similar but not identical. Latencies were prolonged to contralateral stimuli (but for a longer period in PAR an- 
imals). Both of the second, homologous, lesions produced a more severe and enduring neglect, as others have also found (Kennard, 1939; Latto \& Cowey, 1971; Welch \& Stuteville, 1958). Further, neglect from the first lesion was reinstated, since second-lesion latencies were significantly longer in both visual fields. Such a finding implicates the involvement of the undamaged hemisphere in the process of recovery.

Posterior parietal and dorsolateral frontal cortex are, as Mesulam (1981) argued, components of a neural network for attention to events in extrapersonal space. In parietal cortex are mechanisms for sensory schemata, while the arcuate region of frontal cortex regulates motor programs of attention (Heilman \& Valenstein, 1972). In this scheme, sensory representation and motivational significance are linked through the cingulate gyrus; it follows that PAR damage should disrupt visual attention to a greater degree than injury to ARC cortex.

\section{REFERENCES}

ANDERSEN, R. A. (1995). Coordinate transformations and motor planning in posterior parietal cortex. In M. S. Gazzaniga (Ed.), The cognitive neurosciences (pp. 519-532). Cambridge, MA: MIT Press.

BiANCHI, L. (1895). The functions of the frontal lobes. Brain, 18, 497-522.

CritCHLEY, M. (1953). The parietal lobes. London: Arnold.

CrosBy, E. C. (1953). Relation of brain centers to normal and abnormal eye movements in the horizontal plane. Journal of Comparative Neurology, 99, 437-480.

CRowne, D. P. (1983). The frontal eye field and attention. Psychological Bulletin, 93, 232-260.

Crowne, D. P., Dawson, K. A., \& Richardson, C. M. (1989). Unilateral periarcuate and posterior parietal lesions impair conditional position discrimination learning in the monkey. Neuropsychologia, 27, 1119-1127.

Crowne, D. P., Richardson, C. M., \& Dawson, K. A. (1986). Parietal and frontal eye field neglect in the rat. Behavioural Brain Research, 22, 227-231.

Crowne, D. P., Yeo, C. H., \& Russell, I. S. (1981). The effects of unilateral frontal eye field lesions in the monkey: Visual-motor guidance and avoidance behaviour. Behavioural Brain Research, 2, 165-187.

Denny-Brown, D., \& Chambers, R. A. (1958). The parietal lobes and behaviour. In Research publications of the association for research in mental disease (Vol. 36, pp. 35-1 17). Baltimore: Williams \& Wilkins.

DEUEL, R. K. (1987). Neural dysfunction during hemineglect after cortical damage in two monkey models. In M. Jeannerod (Ed.), Neurophysiological and neurophysiological aspects of spatial neglect (pp. 315-334). Amsterdam: Elsevier, North-Holland.

DeUEl, R. K., \& RegaN, D. J. (1985). Parietal hemineglect and motor deficits in the monkey. Neuropsychologia, 23, 305-314.

Drewe, E. A., Ettlinger, G., Milner, A. D., \& Passingham, R. E. (1970). A comparative review of the results of neuropsychological research on man and monkeys. Cortex, 6, 129-163.

EIDELBERG, E., \& SchWARTZ, A. S. (1971). Experimental analysis of the extinction phenomenon in monkeys. Brain, 94, 91-108.

Ettlinger, G., \& Kalsbeck, J. E. (1962). Changes in tactile discrimination and in visual reaching after successive and simultaneous bilateral posterior parietal ablations in the monkey. Journal of Neurology, Neurosurgery, \& Psychiatry, 25, 256-268.
Faugier-Grimaud, S., Frenois, C., \& Peronnet, F. (1985). Effects of posterior parietal lesions on visually guided movements in monkeys. Experimental Brain Research, 59, 128-138.

Faugier-Grimaud, S., Frenois, C., \& Stein, D. G. (1978). Effects of posterior parietal lesions on visually guided behaviour in monkeys. Neuropsychologia, 16, 151-168.

Heilman, K. M., Pandya, D. N., Karol, E. A., \& Geschwind, N. (1971). Auditory inattention. Archives of Neurology, 24, 323-325.

Heilman, K. M., \& Valenstein, E. (1972). Frontal lobe neglect in man. Neurology, 22, 660-664.

Heilman, K. M., Watson, R. T., \& Valenstein, E. (1993). Neglect and related disorders. In K. M. Heilman, R. T. Watson, \& E. Valenstein (Eds.), Clinical neuropsychology (3rd ed., pp. 279-336). New York: Oxford University Press.

KenNARD, M. A. (1939). Alterations in response to visual stimuli following lesions of frontal lobe in monkeys. Archives of Neurology \& Psychiatry, 41, 1153-1165.

LAMOTTE, R. H., \& ACUÑA, C. (1978). Defects in accuracy of reaching after removal of posterior parietal cortex in monkeys. Brain Research, 139, 309-314.

LATTO, R., \& CowEY, A. (1971). Visual field defects after frontal eyefield lesions in monkeys. Brain Research, 30, 1-24.

LYNCH, J. C. (1980). The functional organization of the posterior parietal cortex. Behavioral \& Brain Sciences, 3, 485-534.

LyNCH, J. C., \& MCLAREN, I. W. (1989). Deficits of visual attention and saccadic eye movements after lesions of parieto-occipital cortex in monkeys. Journal of Neurophysiology, 61, 74-90.

Maunsell, J. H. R., \& VAN Essen, D. C. (1983). The connections of the middle temporal visual area (MT) and their relationship to a cortical hierarchy in the macaque monkey. Journal of Neuroscience, 3 , 2563-2586.

Mesulam, M.-M. (1981). A cortical network for directed attention and unilateral neglect. Annals of Neurology, 10, 309-325.

Pandya, D. N., \& Yeterian, E. H. (1985). Architecture and connections of cortical association areas. In A. Peters \& E. G. Jones (Eds.), Cerebral cortex: Vol. 4. Association and auditory cortices (pp. 3-61). New York: Plenum.

Rizzolatti, G., \& Gallese, V. (1987). Mechanisms and theories of spatial neglect. In F. Boller \& J. Grafman (Eds.), Handbook of neuropsychology (pp. 223-246). Amsterdam: Elsevier.

Schwartz, A. S., \& Eidelberg, E. (1968). "Extinction" to bilateral simultaneous stimulation in the monkey. Neurology, 18, 61-68.

SilberpFENNIG, J. (1941). Contributions to the problem of eye movements: III. Disturbances of ocular movements with pseudohemianopsia in frontal lobe tumors. Confina Neurologica, 4, 1-13.

SMITH, W. K. (1949). The frontal eye-fields. In P. C. Bucy (Ed.), The precentral motor cortex (2nd ed., pp. 307-342). Urbana: University of Illinois Press.

STEIN, J. (1978). Effects of parietal lobe cooling on manipulative behaviour in the conscious monkey. In G. Gordon (Ed.), Active touch (pp. 79-90). Oxford: Pergamon.

Valenstein, E., Heilman, K.M., Watson, R.T., \& Van den Abell, T. (1982). Nonsensory neglect from parietotemporal lesions in monkeys. Neurology, 32, 1198-1201.

Weintraub, S., \& Mesulam, M.-M. (1989). Neglect: Hemispheric specialization, behavioral components, and anatomical correlates. In F. Boller \& J. Grafman (Eds.), Handbook of neuropsychology (Vol. 2, pp. 357-374). Amsterdam: Elsevier.

WELCh, K., \& StUTEVILLE, P. (1958). Experimental production of unilateral neglect in monkeys. Brain, 81, 341-347.

(Manuscript received September 22, 1997; revision accepted for publication December 22, 1997.) 